\title{
Anesthetic experience in a pediatric patient with mastocytosis
}

\author{
Youn Yi Jo, Young Jin Chang, Kwang-Sub Kim, and Hyun Jeong Kwak \\ Department of Anesthesiology and Pain Medicine, Gachon University of Medicine and Science Gil Medical Center, Incheon, Korea
}

Mastocytosis represents a spectrum of disease variants characterized by a pathologic increase of mast cells in cutaneous and extracutaneous tissue. Most commonly, the infiltration site of mast cells is skin but, extracutaneous sites including the bone marrow, gastrointestinal tract, liver, spleen and lymphoid tissue have been reported [1]. Patients with mastocytosis have a risk of perioperative reactions via mast cell degranulation and sometimes catastrophic cardiovascular collapse during anesthesia is also possible [2]. We describe the anesthetic management in a pediatric patient with mastocytosis.

A 5-year-old male (weight, $16.5 \mathrm{~kg}$ ) was admitted for elective tonsillectomy and adenoidectomy. He had a history of mastocytosis diagnosed by his dermatologist 3 years ago. He had brownish patches and erythematous urticaria with itching on the whole body from infancy. Serum IgE level using a paper radioimmunosorbent test (PRIST) was 212.54 IU/ $\mathrm{ml}$ (normal value $1-183 \mathrm{IU} / \mathrm{ml}$ ). Mast cells were present as determined by toluidine blue staining of a skin punch biopsy from the abdomen. He had a hoarseness and a hypertrophied tonsil. He took mequitazine, ketotifen fumarate, hydroxyzine hydrochloride for maintenance therapy and also received medications on the morning of the surgery. He had no other history of medical illness except the mastocytosis and his preoperative laboratory tests were normal. He was not premedicated (except for maintenance therapy) and upon arrival to the operating room, his vital signs were: blood pressure at 100/70 $\mathrm{mmHg}$, heart rate at 130 beats/min and pulse oximetry at $99 \%$ before anesthetic induction. Anesthesia was induced with propofol (30 $\mathrm{mg})$, rocuronium $(10 \mathrm{mg}$ ) and alfentanil $(200 \mu \mathrm{g})$. Tracheal intubation was performed using a single lumen, $4.5 \mathrm{~mm}$ internal diameter tube in one attempt without difficulty. Anesthesia was maintained with sevoflurane at $2-3 \mathrm{vol} \%$. The tonsillectomy and adenoidectomy proceeded without an event. At the end of surgery, all anesthetic agents were discontinued and the residual neuromuscular blockade was reversed with pyridostigmine and glycopyrrolate. The tracheal tube was removed when the patient responded to verbal commands and there was sufficient spontaneous respiration and neuromuscular function. There were no signs of reactive airway. The patient remained in the post-anesthetic care unit for 30 minutes event free and was then transferred to the general ward. He had an uneventful recovery and was discharged on postoperative day 2 .

Mast cell intracytoplasic granules contain proinflammatory cytokines and stimulations such as pressure, drugs and allergens may trigger the release of those substances. Symptoms including recurrent hypotension, tachycardia and cardiovascular collapse may develop even with the cutaneous form of mastocytosis [3].

Although the drugs used in the perioperative period may directly or indirectly activate mast cells, preoperative allergy skin tests to drugs used during anesthesia are not recommended. Skin test may not reliable predictors of adverse reactions to drugs because their metabolites are sometimes responsible for the allergic reaction and not the drug itself [4]. Trigger factors could avoid incremental use of mediatortargeting drugs such as $\mathrm{H} 1$ and $\mathrm{H} 2$ blockers. Sometimes, mast

Corresponding author: Hyun Jeong Kwak, M.D., Department of Anesthesiology and Pain Medicine, Gachon University of Medicine and Science Gil Medical Center, 1198, Guwol-dong, Namdong-gu, Incheon 405-760, Korea. Tel: 82-32-460-3637, Fax: 82-32-469-6319, E-mail: hyun615@gilhospital.com (c) This is an open-access article distributed under the terms of the Creative Commons Attribution Non-Commercial License (http:// creativecommons.org/licenses/by-nc/3.0/), which permits unrestricted non-commercial use, distribution, and reproduction in any medium, provided the original work is properly cited. 
cell stabilizers like sodium cromoglycate or glucocorticoids might be beneficial in the case of abdominal cramping or cardiovascular symptoms [5]. However, routine prophylactic anti-histamine and steroids were not used. Instead, when patients were taking chronic therapy, their medications were continued as scheduled as previously reported in the anesthetic management of 29 procedures [4]. Further, that study, there were no obvious restrictions of anesthetic agents and no serious complications were reported [4].

Pediatric patients with mastocytosis often need diagnostic and therapeutic procedures that require general anesthesia. Because mast cells are implicated in the pathophysiology of anaphylaxis, drugs used in anesthesia which may degranulate mast cells raise concerns about the potential for adverse reactions in patients with mastocytosis. Although routine anesthetic techniques are not necessarily warranted, an understanding of the anesthetic implications of the disease and meticulous preparation to treat possible adverse events are advised.

\section{References}

1. Korenblat PE, Wedner HJ, Whyte MP, Frankel S, Avioli LV. Systemic mastocytosis. Arch Intern Med 1984; 144: 2249-53.

2. Tirel O, Chaumont A, Ecoffey C. Circulatory arrest in the course of anesthesia for a child with mastocytosis. Ann Fr Anesth Reanim 2001; 20: 874-5.

3. Castells M, Austen KF. Mastocytosis: mediator-related signs and symptoms. Int Arch Allergy Immunol 2002; 127: 147-52.

4. Carter MC, Uzzaman A, Scott LM, Metcalfe DD, Quezado Z. Pediatric mastocytosis: Routine anesthetic management for a complex disease. Anesth Analg 2008; 107: 422-7.

5. Ahmad N, Evans P, Lloyd-Thomas AR. Anesthesia in children with mastocytosis-a case based review. Paediatr Anaesth 2009; 19: $97-$ 107. 